\title{
Low-Cost Synthesis of Carbon Nanohorns by Nitrogen-Injected Arc-in-Water System: Use of Low Purity Electrode for High Yield Production
}

\author{
Noriaki Sano ${ }^{1}$, Yoshinaga Yasumura ${ }^{1}$, Yuu Kimura ${ }^{1}$, Atsuhi Toyoda ${ }^{2}$, Katsumi Hirano ${ }^{2}$ \\ ${ }^{1}$ University of Hyogo, Department of Mechanical and System Engineering, 2167 Shosha, Himeji, Japan \\ Fax: 81-79-267-4845, e-mail: sano@eng.u-hy ogo.ac.jp \\ ${ }^{2}$ Himeka Engineering Co., Ltd, 2-121, 2-121 Tegara, Himeji 670-0972
}

\begin{abstract}
Single-walled carbon nanohorns (SWCNHs) can be produced by an arc-in-water system, in which $\mathrm{N}_{2}$ gas is injected in an arc plasma zone in a hollow graphite cathode. To decrease the cost for synthesis, it is important to optimize the reaction condition when low cost electrodes (low purity graphite) are used because high purity graphite is fairly costly. In the present study, graphite electrode of a low graphite purity (C:97.5\%, $\mathrm{SiO}_{2}: 1.4 \%, \mathrm{Al}_{2} \mathrm{O}_{3}: 0.38 \%$, $\mathrm{Fe}_{2} \mathrm{O}_{3}: 0.29 \%$, etc.) was used for the electrodes, and the investigation of the operational paramters in the $\mathrm{N}_{2}$-injected arc-in-water method was carried out regarding the depth of the hole on cathode and velocity of the electrode motion to keep the arc plasma. It was observed in a transmission electron microscope that the purity of the SWCNHs from the low-purity graphite electrodes seemed as 70-80\%. As a result, the cost to synthesize SWCNHs became one order magnitude lower compared with the conventional condition using high purity graphite electrodes. At this condition, the yield and the production rate of SWCNHs were about $8 \%$ and $18 \mathrm{~g} / \mathrm{h}$, respectively. In addition, the mechanism of the effect of the above parameters is discussed based on the resident time and the concentration of carbon vapor inside the cathode hole.
\end{abstract}

Key words: carbon nanohorn, arc discharge, liquid nitrogen

\section{INTRODUCTION}

These days, the development of synthesis method and applications of nanotube-family materials have been attracting hot attention because of their promising characteristics. Multi-walled carbon nanotubes and single-walled carbon nanotubes are especially known as such materials. In addition, single-walled carbon nanohorns (SWCNHs) [1] also receive much interest for application to the use of catalyst-support in fuel cell, gas fuel absorption, solid lubricant, and so forth. Since SWCNHs were firstly reported by lijima et. al., who synthesized SWCNHs by laser ablation method [1], several methods to synthesize SWCNHs have been developed based on reaction systems using arc discharge. For example, arc discharge between graphite electrodes in liquid nitrogen can generate SWCNHs as a simple manner [2]. As the significant aspect of this method, its set-up can be built with extremely low cost, and thus this method is very helpful for people who want to obtain relatively high purity SWCNHs readily. Except the method using arc discharge in liquid nitrogen, torch arc in open air [3] and arc in gas with preheated electrodes [4] have been reported.

Since one of the authors reported the synthesis of SWCNHs by the method with are in liquid nitrogen, we have been investigated this system. In such activities, as we were motivated to use water instead of liquid nitrogen because water is much easy to use in terms of the cost and physical properties, 'arc-in-water with gas-injection' has been contrived [5]. In the first report about this system [5], the yield (weight-based ratio of production of as-grown SWCNHs to the consumption of graphite electrode) and the production rate were $2 \%$ and $3.4 \mathrm{~g} / \mathrm{h}$, respectively. Since then, we have been searching optimized condition to obtain SWCNHs with high yield to decrease the synthesis cost [6]. For the motivation to pursue the low cost production of SWCNHs, we used low-purity graphite (ash content $=2.5 \%$ ) whose cost is approximately 0.05 times compared with the high purity one conventionally used, and found that the production rate of SWCNHs from low-purity graphite seemed extremely low at the conventional condition Nevertheless, the present study reveals that the production rate and the yield of SWCNHs can be significantly improved if the condition is optimized. Here, we report the influence of the depth of the cathode hole and the velocity of the electrode motion to keep the arc discharge on the characteristics of SWCNHs synthesis.

\section{EXPERIMENTAL}

Fig. 1 shows the apparatus and the structure of the cathode used in this study. A graphite rod (diameter $=3.3 \mathrm{~mm}$ ) and a hollow graphite rod with a large hole (diameter $=12.3 \mathrm{~mm}$, diameter of the large hole $=8 \mathrm{~mm}$, depth of hole $=25-35 \mathrm{~mm}$ ) were used for anode and cathode, respectively. On the cathode, two holes to inject $\mathrm{N}_{2}$ gas into the arc zone were drilled on the other side of the large hole. These electrodes were submerged in water while the arc discharge was generated. The gas flow rate of $\mathrm{N}_{2}$ injection was kept 5 $\mathrm{L} / \mathrm{min}$. When arc discharge was generated, the anode rod was inserted into the cathode hole, which were connected with d.c. powder generator (Sindaiwa, 
STW201A). When arc discharge was generated with $\mathrm{N}_{2}$ injection, carbon vapor was expected to be quenched rapidly in the fast $\mathrm{N}_{2}$ flow until the carbon vapor was expelled out from the cathode hole. SWCNHs produced were conveyed to the water surface with gas bubble, and they floated there. We collected the floating as-grown SWCNHs, and measured the weight-basis yield of SWCNHs.

In this study, the electrode motion was manipulated by an electric slider driven by a stepping motor. To initiate the arc discharge, we employed touch-and-release way. After the arc discharge was started, the discharge was maintained by moving anode upward at a constant velocity. This velocity was controlled in the range of $0.75-6.00 \mathrm{~mm} / \mathrm{s}$. During the arc discharge, only the anode is continuously consumed. Thus, the electrode consumption rate can be estimated as the velocity of the anode motion multiplied by the cross-section area of the anode and the density of the graphite anode $\left(1.7 \mathrm{~g} / \mathrm{cm}^{3}\right)$. It should be noted that the production rate of SWCNHs is consistent with the value obtained by multiplication of this anode consumption rate by the weight-basis yield of SWCNHs.

The as-grown SWCNHs were analyzed by a transmission electron microscope (TEM)(JEOL, JEM-2010). Also, the specific surface area of the

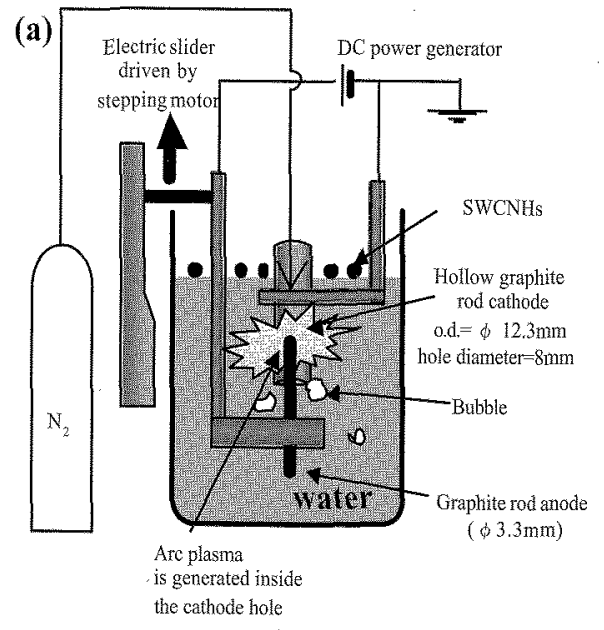

(b)

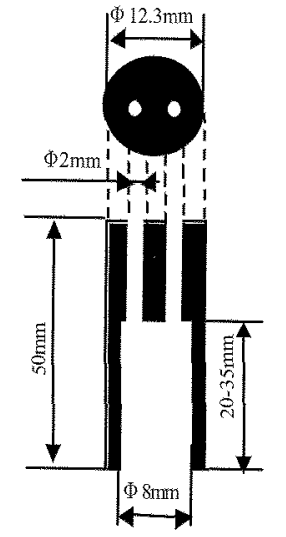

Fig. 1 (a) Schematic of the apparatus of arc-in-water with $\mathrm{N}_{2}$-injection to produce SWCNHs. (b) Dimensions of the hollow cathode. products were obtained by $\mathrm{N}_{2}$ adsorption with BET scheme at liquid nitrogen temperature (Bel-Japan, Bel-mini)

\section{RESULTS AND DISCUSSION}

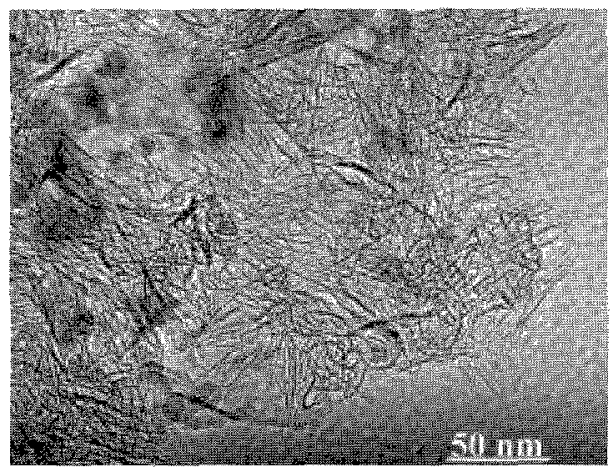

Fig. 2 Typical TEM image of SWCNHs produced by the arc-in-water with $\mathrm{N}_{2}$ injection. (depth of cathode hole $=30 \mathrm{~mm}$; anode ascending velocity $=2.25 \mathrm{~mm} / \mathrm{s}$ )

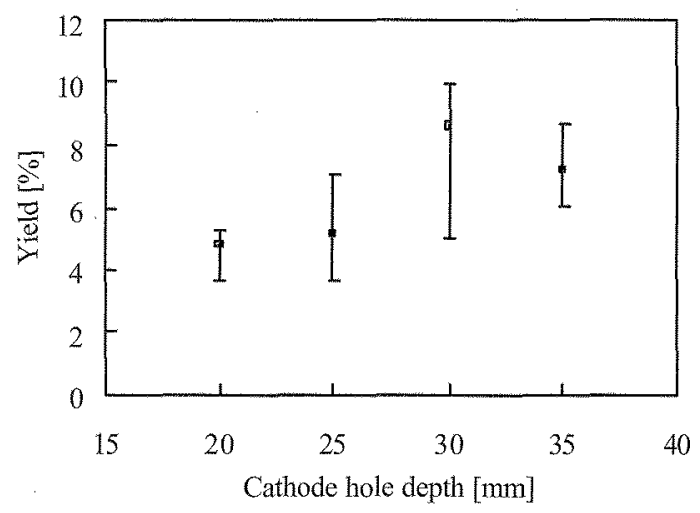

Fig. 3 The influence of the depth of the cathode hole on the yield of as-grown SWCNHs. (anode ascending velocity $=2.25 \mathrm{~mm} / \mathrm{s}$ )

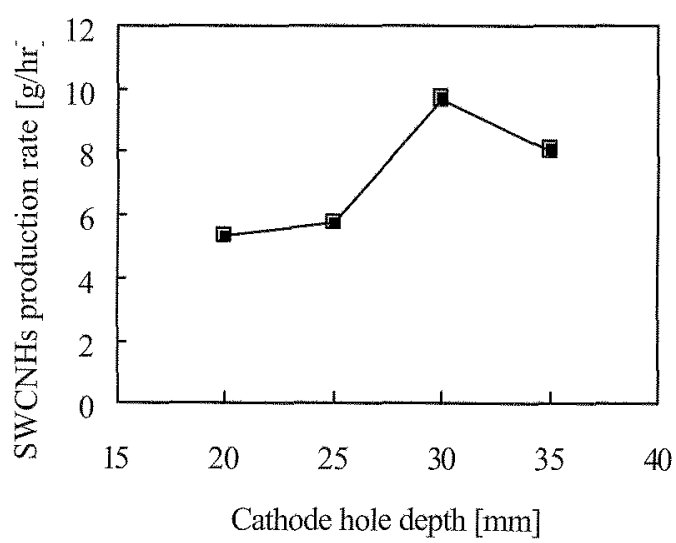

Fig. 4 The influence of the depth of the cathode hole on the production rate of as-grown SWCNHs. (anode ascending velocity $=2.25$ $\mathrm{mm} / \mathrm{s}$ ) 
2.1 Influence of the depth of the cathode hole on the characteristics of SWCNHs production.

Fig. 2 shows a typical TEM image of SWCNHs obtained by our system. The purity of SWCNHs seemed to be $70-80 \%$ in the TEM observation at the optimized condition explained latter. Here, the most of the impurity seemed amorphous carbon.

Fig. 3 shows the influence of the depth of the cathode hole on the weight-basis yield of as-grown SWCNHs. It is shown that the yield increases with the hole depth up to $30 \mathrm{~mm}$, and decreases when the hole depth is excessively large. Fig. 4 shows the influence of the depth of the cathode hole on the production rate of SWCNHs. Here, the production rate of SWCNHs can be maximized at $30 \mathrm{~mm}$, of which tendency is similar to the case of the yield. Fig. 5 shows the specific surface area of the as-grown SWCNHs. Here, the specific surface area also increases with the hole depth up to $30 \mathrm{~mm}$, and decreases when the depth becomes above that. In the tendency of the specific surface area, its increase in the range of below $30 \mathrm{~mm}$ is relatively gentle, and it decreases sharply in the range of the large hole depth. As we consider that the higher specific surface area

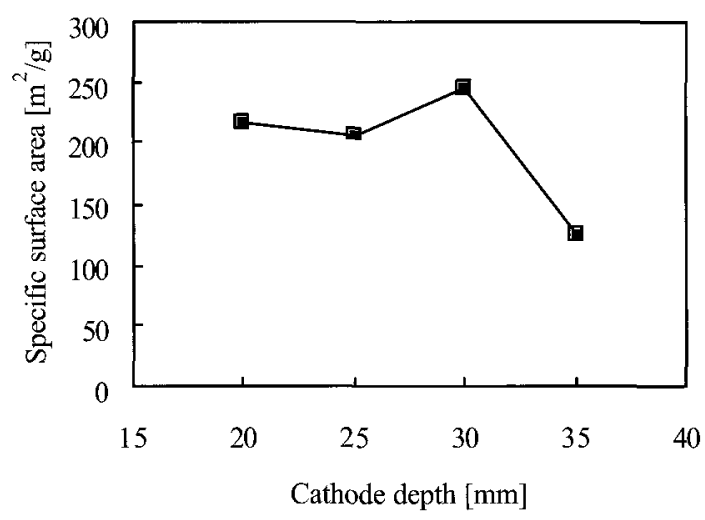

Fig. 5 The influence of the depth of the cathode hole on the specific surface area of as-grown SWCNHs. (anode ascending velocity $=2.25$ $\mathrm{mm} / \mathrm{s}$ )

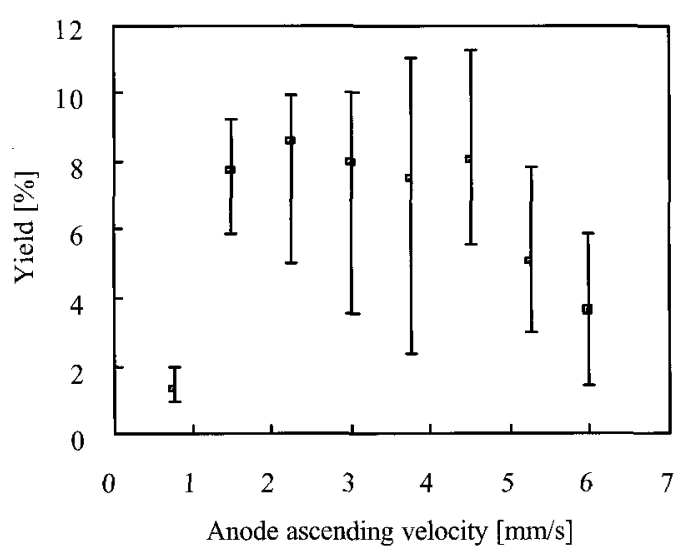

Fig. 6 The influence of the anode ascending velocity toward the cathode hole on the yield of as -grown SWCNHs. (depth of cathode hole $=30 \mathrm{~mm}$.) indicates the higher purity of SWCNHs, the purity should become maximum when the hole depth is $30 \mathrm{~mm}$. From the results regarding the yield, the production rate, and the specific surface area, we decided to employ $30 \mathrm{~mm}$ for the hole depth in further investigation.

2.2 Influence of the velocity of the anode ascending motion toward the cathode on the characteristics of SWCNHs production

Fig. 6 shows the yield of as-grown SWCNHs related with the velocity of the anode ascending motion. It should be noted that the anode consumption rate can increase proportionally to this velocity. As a result, evaporation of carbon from the anode should increase with the anode ascending velocity, so that the concentration of carbon vapor in the arc plasma zone should increase with this velocity. In Fig. 6, the yield is relatively low when the anode ascending velocity is so low as $0.75 \mathrm{~mm} / \mathrm{s}$. In the range of $1.5-4.5 \mathrm{~mm} / \mathrm{s}$, the influence of the anode ascending velocity on the yield is not obvious. When the anode ascending velocity is so

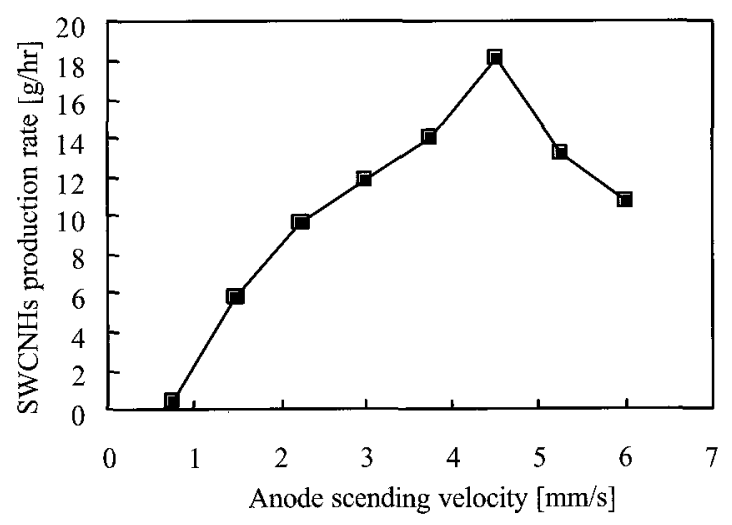

Fig. 7 The influence of the anode ascending velocity toward the cathode on the production rate of as - grown SWCNHs. (depth of cathode hole $=30 \mathrm{~mm}$.)

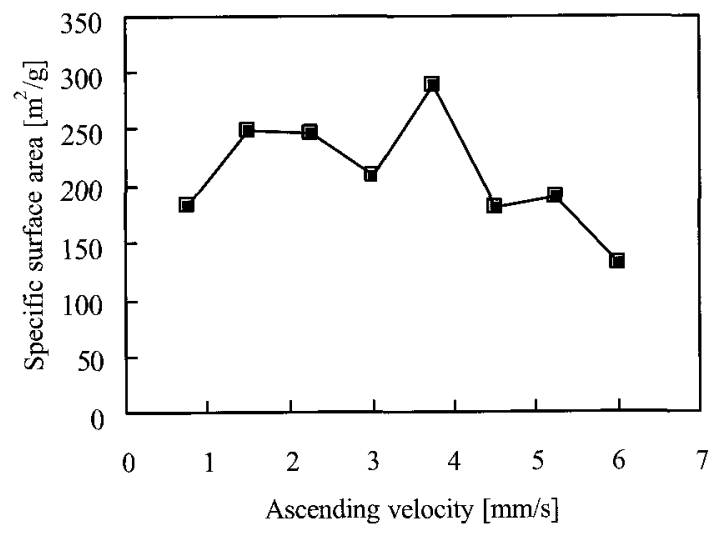

Fig. 8 The influence of the anode ascending velocity toward the cathode on the specific surface area of as-grown SWCNHs. (depth of cathode hole $=30 \mathrm{~mm}$.) 


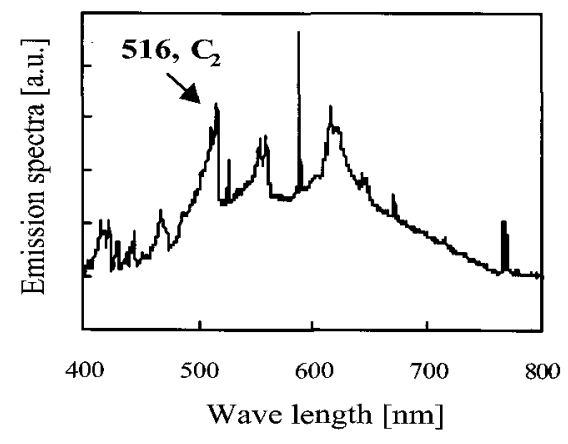

Fig. 9 Emission spectra from arc in the hollow cathode during the synthesis of SWCNHs. (velocity of anode motion $=2.25 \mathrm{~mm} / \mathrm{s}$, depth of the cathode hole $=30 \mathrm{~mm}$.)

high as $5.25-6 \mathrm{~mm} / \mathrm{s}$, the yield becomes low. In Fig. 7 , the production rate of as-grown SWCNHs is shown against the anode ascending velocity. One can obviously see that the SWCNHs production rate is maximized at $4.5 \mathrm{~mm} / \mathrm{s}$. Fig. 8 shows the specific surface area of as-grown SWCNHs related with the anode ascending velocity. It seems that the specific surface area becomes the highest when the anode ascending velocity is 3.75 $\mathrm{mm} / \mathrm{s}$. As mentioned above, we consider that the high specific surface area indicates that the purity of SWCNHs is high in the products. Thus, with the consideration of the yield and production rate, the range of $3.75-4.5 \mathrm{~mm} / \mathrm{s}$ of the anode ascending velocity is recommended to achieve optimized condition to obtain SWCNHs.

2.3 Mechanism of the effects of the above operational parameters on the characteristics of the SWCNHs production

When arc discharge is generated in our system, carbon vapor is generated in the arc plasma zone. Fig. 9 shows the emission spectra of arc plasma at a typical condition in this study. The peak at $516 \mathrm{~nm}$ of wave length may indicate the existence of the $G$ cluster radical. We consider that the appropriate quenching rate of carbon vapor should be necessary when SWCNHs are produced. If the carbon vapor is expelled out too quickly when the deth of the cathode hole is shallow, the carbon vapor is reacted with water outside the cathode, and carbon vapor is converted to $\mathrm{H}_{2}$ and $\mathrm{CO}$ by a reaction $\left(\mathrm{C}+\mathrm{H}_{2} \mathrm{O}->\mathrm{H}_{2}+\mathrm{CO}\right)$ [7]. As a result, during the experiment to synthesize SWCNHs by the present apparatus, we sometimes observed flame above the water surface. To reduce such unwanted reaction, the depth of the cathode hole should not be too short. However, if the cathode hole is too deep, the resident time of the carbon vapor in the cathode becomes too long. In such condition, the quenching rate of carbon vapor may not be high enough and the products may further converted to graphite flakes. This is why there is an optimized value of the depth of the cathode hole.

In the experiment with the varied anode ascending velocity, we found that the arc discharge can be stably continued at a constant velocity in some velocity range. Nevertheless, the emission rate of the carbon vapor should be different when the anode ascending velocity is changed. As mentioned above, therefore the concentration of the carbon vapor should increase with the anode ascending velocity. Thus, the concentration of carbon vapor may not reach an appropriate quantity for SWCNHs formation if the anode ascending velocity is too low. If the anode ascending velocity is too high, the concentration of carbon vapor may be too high so that high density product such as graphite impurities are preferably formed. For such reason, there is an optimized value of the anode ascending velocity.

To realize the production of high purity SWCNHs from low purity graphite including metallic oxides, these impurities should be removed in the SWCNHs formation process. It should be noted that the melting points of these impurities are blow $2000{ }^{\circ} \mathrm{C}$, and that of carbon is above $4000{ }^{\circ} \mathrm{C}$. Thus, if the region where SWCNHs are formed has the temperature above $2000^{\circ} \mathrm{C}$, these impurities can be removed from the SWCNHs products due to the difficulty of solidification of the impurities.

\section{CONCLUSION}

SWCNHs were synthesized by the arc-in-water with $\mathrm{N}_{2}$ injection. The graphite electrode of a low graphite purity $\left(\mathrm{C}: 97.5 \%, \quad \mathrm{SiO}_{2}: 1.4 \%, \quad \mathrm{Al}_{2} \mathrm{O}_{3}: 0.38 \%\right.$, $\mathrm{Fe}_{2} \mathrm{O}_{3}: 0.29 \%$, etc.) was used for the electrodes, to optimize the depth of the cathode hole and the velocity of the anode ascending motion. In TEM observation, the purity of as-grown SWCNHs seemed to be $70-80 \%$. It is found that the condition can be optimized at the depth of the cathode hole and the anode ascending velocity, $30 \mathrm{~mm}$ and $3.75-4.5 \mathrm{~mm} / \mathrm{s}$ respectively, so that the production rate and the yield can reach about $18 \mathrm{~g} / \mathrm{h}$ and $8 \%$. It should be reminded that this study have found a preferable condition to use the low cost electrodes (one-twenties cost of the conventional ones) and the yield has become about nine times higher than the value firstly reported [5]. As a result, considering the cost of the electrodes and the yield, the total cost to obtain a unit mass of SWCNHs with low-purity (low cost) electrodes can be about two-order cheaper than with high-purity ones when the optimized condition is employed.

\section{ACKNOWLEDGMENT}

This work is partially support ed by Hyogo Prefecture COE program and Grants-in-Aid for Scientific Research (for young scientists A) byMinistry of Education, Culture, Sports, Science and Technology -Japan.

\section{REFERENCES}

[1] S. Ijjima, M. Yudasaka, R. Yamada, S. Bandow, K. Suenaga, F. Kokai and K. Takahashi, Chem. Phys. Lett. 309, 165-70 (1999).

[2] N. Sano, J. Nakano and T. Kanki, Carbon 42, 667-91 (2004).

[3] H. Takikawa, M. Ikeda, K. Hirahara, Y. Hibi, Y. Tao, P.A. Ruiz Jr., T. Sakakibara, S. Itoh and S. Iijima, Physica B, 323, 277-79 (2002)

[4] T. Yamaguchi, S. Bandow and S Iijima, Chem. Phys. Lett. 389, 181-85 (2004).

[5] N. Sano, J. Phys. D: Appl. Phys. 37, L17-L20 (2004). [6] N. Sano, Yuu Kimura, Y. Yasumura, J. Mat. Chem. 18, 1555-60 (2008).

[7] Y. L. Hsin, K. C. Hwang, R.-R. Chen, J.-J. Kai, $A d v$. Mater. 13, 830-3 (2001). . 